\title{
Preventing heat illness in the anticipated hot climate of the Tokyo 2020 Summer Olympic Games
}

\author{
Takeyasu Kakamu $^{1 *}$ DD, Koji Wada ${ }^{2 \dagger}$, Derek R. Smith ${ }^{3}$, Shota Endo ${ }^{1}$ and Tetsuhito Fukushima ${ }^{1}$
}

\begin{abstract}
Amid the effects of global warming, Tokyo has become an increasingly hot city, especially during the summertime. To prepare for the upcoming 2020 Summer Olympics and Paralympics in Tokyo, all participants, including the athletes, staff, and spectators, will need to familiarize themselves with Tokyo's hot and humid summer conditions. This paper uses the wet-bulb globe temperature (WBGT) index, which estimates the risk of heat illness, to compare climate conditions of sports events in Tokyo with the conditions of the past three Summer Olympics (held in Rio de Janeiro, London, and Beijing) and to subsequently detail the need for establishing appropriate countermeasures. We compared WBGT results from the past three Summer Olympics with the same time periods in Tokyo during 2016. There was almost no time zone where a low risk of heat illness could be expected during the time frame of the upcoming 2020 Tokyo Olympics. We also found that Tokyo had a higher WBGT than any of those previous host cities and is poorly suited for outdoor sporting events. Combined efforts by the official organizers, government, various related organizations, and the participants will be necessary to deal with these challenging conditions and to allow athletes to perform their best, as well as to prevent heat illnesses among staff and spectators. The sporting committees, as well as the Olympic organizing committee, should consider WBGT measurements in determining the venues and timing of the events to better avoid heat illness and facilitate maximum athletic performance.
\end{abstract}

\section{Background}

Amid the effects of global warming, heat-related health risks are increasing [1] especially in sporting events [2,3]. Global warming is believed to be an ongoing phenomenon, and thermal environment management, particularly heat stress, is growing in importance. Caution is therefore needed to help guard against these health risks during summer sporting events [4]. The 2016 Summer Olympics held in the tropical city of Rio de Janeiro, for example, faced potential environment conditions of 19.6 to $28.7{ }^{\circ} \mathrm{C}$ and $\sim 71 \%$ relative humidity [5]. The high visibility of international athletic events such as the Summer Olympics represents just a small fraction of the intense physical exertion undertaken outdoors, and increasing restrictions on when, where, and how the Games can be held in consideration of extreme heat conditions

\footnotetext{
* Correspondence: bamboo@fmu.ac.jp

${ }^{\dagger}$ Equal contributors

'Department of Hygiene and Preventive Medicine, School of Medicine, Fukushima Medical University, Hikarigaoka 1, Fukushima 960-1295, Japan Full list of author information is available at the end of the article
}

suggest the growing magnitude of this issue [6]. On the other hand, heat illness in athletes is considered to be preventable and countermeasures are necessary for team staffs [7].

Tokyo will host the Summer Olympics from 24 July to 9 August 2020 [8]. Tokyo is the world's largest metropolitan area [9], and the effects of this vast urbanization further aggravate the damp thermal environment [10]. Recently, the total number of individuals suffering from heat illness is rising in Tokyo [1]. Interestingly, the previous Tokyo Summer Olympics of 1964 were actually held in autumn (10-24 October), and therefore, the upcoming 2020 event will present even greater heat-related challenges.

The most common recommendation to currently follow is that sporting event organizers reschedule or cancel an event based on the wet-bulb globe temperature (WBGT), an index based on a combination of ambient temperature, relative humidity, the heat-load impact of solar radiation, and the cooling power of wind $[4,11]$. WBGT is a 
validated empirical index of environmental heat stress and has been awarded an ISO (ISO/DIS 7933 1984) certification $[12,13]$. WBGT was initially developed by the US military [14] in recognition that heat illness is caused by the combined effects of high temperatures, high humidity, and solar radiation on the human body $[15,16]$. Research utilizing the WBGT also focused on developing safe limits for physical exertion in hot environments [17]. The index later became popular in sports medicine via the American College of Sports Medicine (ACSM) (Table 1) [15] and was subsequently adopted by various other sporting federations. The International Tennis Federation (ITF), for instance, uses it to decide on the suspension of play, while the Federation of International Football Association (FIFA) uses it to determine breaks for players to cool down $[18,19]$.

Several studies have estimated potential WBGT values expected during the 2020 Tokyo Olympics and have suggested a time shift for events [20, 21]. However, the temperature of Tokyo is high even at midnight, so it is unknown whether such a time shift would be effective. The present study aimed to compare the WBGT measurements by time zone in Tokyo with those of the past three Summer Olympics and to detail the need for establishing appropriate countermeasures for the upcoming 2020 Olympics in Tokyo.

\section{Method of assessment of WBGT index for recent Summer Olympics and Tokyo}

We referred to WBGT measurements for the host cities of the past three Summer Olympics (in Rio de Janeiro, London, and Beijing). Although WBGT and global temperatures are not always maintained in weather records, Australia's Bureau of Meteorology approximates it from air temperature and relative humidity as follows [12].

The simplified formula is:

$$
\begin{aligned}
& \text { WBGT }=0.567 \times \mathrm{Ta}+0.393 \times(\mathrm{rh} / 100 \times 6.105 \times \\
& \exp (17.27 \times \mathrm{Ta} /(237.7+\mathrm{Ta})))+3.94 \\
& \text { where: } \\
& \mathrm{Ta}=\text { air }(\text { dry }- \text { bulb }) \text { temperature }\left({ }^{\circ} \mathrm{C}\right) \\
& \mathrm{rh}=\text { relative humidity }(\%)
\end{aligned}
$$

The formula assumes a moderately high radiation level in light wind conditions. We note that the calculated WBGT can estimate daytime conditions accurately but may overestimate nighttime and early morning conditions [12].

Temperature and humidity data for every $3 \mathrm{~h}$ on event dates are recorded on the World Weather Online website [22]. To estimate and compare with past host cities, we used the past 10 years (2008-2017) of data for the same

\begin{tabular}{|c|c|c|c|c|}
\hline \multicolumn{2}{|l|}{ WBGT } & \multirow{2}{*}{$\begin{array}{l}\text { Continuous activity and } \\
\text { competition }\end{array}$} & \multicolumn{2}{|l|}{ Training and non-continuous activity } \\
\hline${ }^{\circ} \mathrm{F}$ & ${ }^{\circ} \mathrm{C}$ & & Non-acclimatized, unfit, high-risk individuals ${ }^{a}$ & Acclimatized, fit, low-risk individuals ${ }^{a, b}$ \\
\hline$\leq 50.0$ & $\leq 10.0$ & $\begin{array}{l}\text { Generally safe; EHS can occur } \\
\text { associated with individual factors }\end{array}$ & Normal activity & Normal activity \\
\hline $50.1-65.0$ & $10.1-18.3$ & Generally safe; EHS can occur & Normal activity & Normal activity \\
\hline $65.1-72.0$ & $18.4-22.2$ & $\begin{array}{l}\text { Risk of EHS and heat illness begins } \\
\text { to rise; high-risk individuals should } \\
\text { be monitored or not compete }\end{array}$ & $\begin{array}{l}\text { Increase the rest: work ratio. } \\
\text { Monitor fluid intake. }\end{array}$ & Normal activity \\
\hline $72.1-78.0$ & $22.3-25.6$ & Risk for all competitors is increased & $\begin{array}{l}\text { Increase the rest: work ratio; } \\
\text { decrease total duration of activity. }\end{array}$ & Normal activity monitor fluid intake. \\
\hline $78.1-82.0$ & $25.7-27.8$ & $\begin{array}{l}\text { Risk for unfit, non-acclimatized } \\
\text { individuals is high }\end{array}$ & $\begin{array}{l}\text { Increase the rest to work ratio; } \\
\text { decrease intensity and total } \\
\text { duration of activity. }\end{array}$ & Normal activity monitor fluid intake. \\
\hline $82.1-86.0$ & $27.9-30.0$ & Cancel level for EHS risk & $\begin{array}{l}\text { Increase the rest to work ratio to } 1: 1 \text {, } \\
\text { decrease intensity and total duration } \\
\text { of activity. Limit intense exercise. } \\
\text { Watch at-risk individuals carefully. }\end{array}$ & $\begin{array}{l}\text { Plan intense or prolonged exercise } \\
\text { with discretionc, watch at-risk } \\
\text { individuals carefully }\end{array}$ \\
\hline $86.1-90.0$ & $30.1-32.2$ & & Cancel or stop practice and competition. & $\begin{array}{l}\text { Limit intense exercise }{ }^{c} \text { and total daily } \\
\text { exposure to heat and humidity; } \\
\text { watch for early signs and symptoms }\end{array}$ \\
\hline$\geq 90.1$ & $\geq 32.3$ & & Cancel exercise. & $\begin{array}{l}\text { Cancel exercise uncompensable } \\
\text { heat stress }{ }^{d} \text { exists for all athletes }{ }^{c}\end{array}$ \\
\hline
\end{tabular}
dates in Tokyo (the place of the new Tokyo Olympic Stadium). WBGT measurements at 00:00, 03:00, 06:00, 09:00, 12:00, 15:00, 18:00, and 21:00 were utilized.

Table 1 Wet-bulb globe temperature (WBGT) levels for modification or cancelation of workouts or competition for healthy adults [15] 


\section{Comparison of WBGT at previous three Summer Olympics with current summer climate in Tokyo}

Table 2 shows the median and 25th-75th percentile WBGT by time of day for each city. Tokyo recorded the highest WBGT at each time, and the median WBGT was at a "Cancel level for EHS risk for continuous activity and competition" at all times. From 09:00 to 18:00, the median WBGT was at "cancel exercise uncompensable heat stress exists for all athletes" $\left(33,34,34\right.$, and $33{ }^{\circ} \mathrm{C}$ at 09:00, 12:00, 15:00, and 18:00, respectively). In fact, none of the measured WBGT predicted a low risk of heat illness. These data suggest that Tokyo's climate poses an extremely high risk for outdoor sports in the summer.

We plotted days when the maximum WBGT was $\geq 27.9{ }^{\circ} \mathrm{C}$ ("cancel level for EHS risk for continuous activity and competition" as per the ACMS classification) and $\geq 30.1{ }^{\circ} \mathrm{C}$ ("cancel or stop practice and competition" per ACMS classification) as reported in data from the Ministry of the Environment, Japan (Fig. 1) [21]. In 2010, the days of maximum WBGT in Tokyo $\geq 27.9$ or $30.1{ }^{\circ} \mathrm{C}$ showed an increase and have maintained a high level in each summer (July-September) since then. These data, therefore, suggest the risk of heat illness is also increasing in recent years. Not only for outdoor events but also indoor sporting events present a risk of heat illness during the daytime because spectators can be expected to move around both inside and outside the venue.

\section{Desirable preventive measures from the sports organizing committees}

We determined that the WBGT during the Tokyo 2020 Olympics would likely be classified as high risk to a point where stoppage of play would be recommended at almost any time. Establishing and implementing effective countermeasures against heat illness is a vital task in preparations for the event. These measurements must be led by the official organizers, government, various related organizations, and the participants who will also need to take a number of preparatory measures and to establish an appropriate emergency medical system during the upcoming Olympic Games.
In cooperation with individual sporting associations, WBGT scores should be used as a standard when creating guidelines for measures taken to prevent heat illness. The Japanese Ministry of the Environment, for example, has published heat illness guidelines for summer events for event organizers and facility managers [23]. WBGT scores around and in venues should be considered in determining which venues are suitable. In addition, the effect of heat stress can also differ between individuals, and therefore, it is necessary to take measures according to their attributes such as athletes, staff, and spectators. Heat illness involves a complex interaction between environmental heat strain, clothing, and human thermal physiology [11]. Preventive measures should therefore consider various strategies and management protocols specifically targeting environmental heat stress.

The ACSM has declared that all summer events should be scheduled for the early morning, ideally before 08:00, or in the evening after 18:00, to minimize solar radiation [15]. In Tokyo, for almost all daytime hours during equivalent event dates in 2016, the WBGT records demonstrated levels of "Cancel level for EHS risk for continuous activity and competition" or "cancel or stop practice and competition," and therefore, even conducting these events in the early morning and nighttime might not be sufficient to avert heat illness. As heat illness is also related to the exercise intensity and duration, desirable schedules must also be matched to individual sports.

Acclimatization to heat can be critical in preventing heat illness, as it increases tolerance, adjusts the body's sweating mechanism (such as the threshold body temperature for sweating), causes excessive sweating, and decreases the amount of sodium lost through sweat [24]. Recently, heat acclimatization before competing in the heat has become an important measure for athletes $[4,25]$, and heat acclimation has also become part of the training regimen for sports competition [24, 25]. The risk of heat illness among athletes seems to be not so high despite the high WBGT index [26]. In 2015, the International Association of Athletics Federations (IAAF) World Athletics Championships in Beijing, China, only $15 \%$ of athletes were heat acclimatized even though hot and humid conditions were expected [27].

Table 2 Wet-bulb globe temperature (WBGT) by time of day in the previous three Summer Olympics and the expected periods of the Tokyo 2020 Summer Olympics

\begin{tabular}{lllllllll}
\hline & $00: 00$ & $03: 00$ & $06: 00$ & $09: 00$ & $12: 00$ & $15: 00$ & $18: 00$ & $21: 00$ \\
\hline Tokyo & $30(29-32)$ & $30(28-31)$ & $30(28-31)$ & $33(31-35)$ & $34(32-36)$ & $34(32-36)$ & $33(31-34)$ & $31(30-33)$ \\
Rio de Janeiro & $23(22-24)$ & $23(21-23)$ & $22(20-23)$ & $26(25-28)$ & $31(27-32)$ & $30(26-31)$ & $29(25-31)$ & $26(24-27)$ \\
London & $18(16-19)$ & $17(15-18)$ & $18(16-19)$ & $21(19-22)$ & $22(21-24)$ & $22(21-24)$ & $21(21-24)$ & $19(18-20)$ \\
Beijing & $21(20-25)$ & $21(20-24)$ & $24(22-27)$ & $29(27-31)$ & $31(30-32)$ & $31(30-32)$ & $27(26-28)$ & $24(22-25)$ \\
\hline
\end{tabular}

Median (25th-75th percentile) WBGT ( ${ }^{\circ} \mathrm{C}$ ) Tokyo: 24 July to 9 August from 2008 to 2017 (dates scheduled for Tokyo 2020 Summer Olympics) Rio de Janeiro: 5-21 August 2016 London: 25 July-12 August 2012 Beijing: 8-24 August 2008 


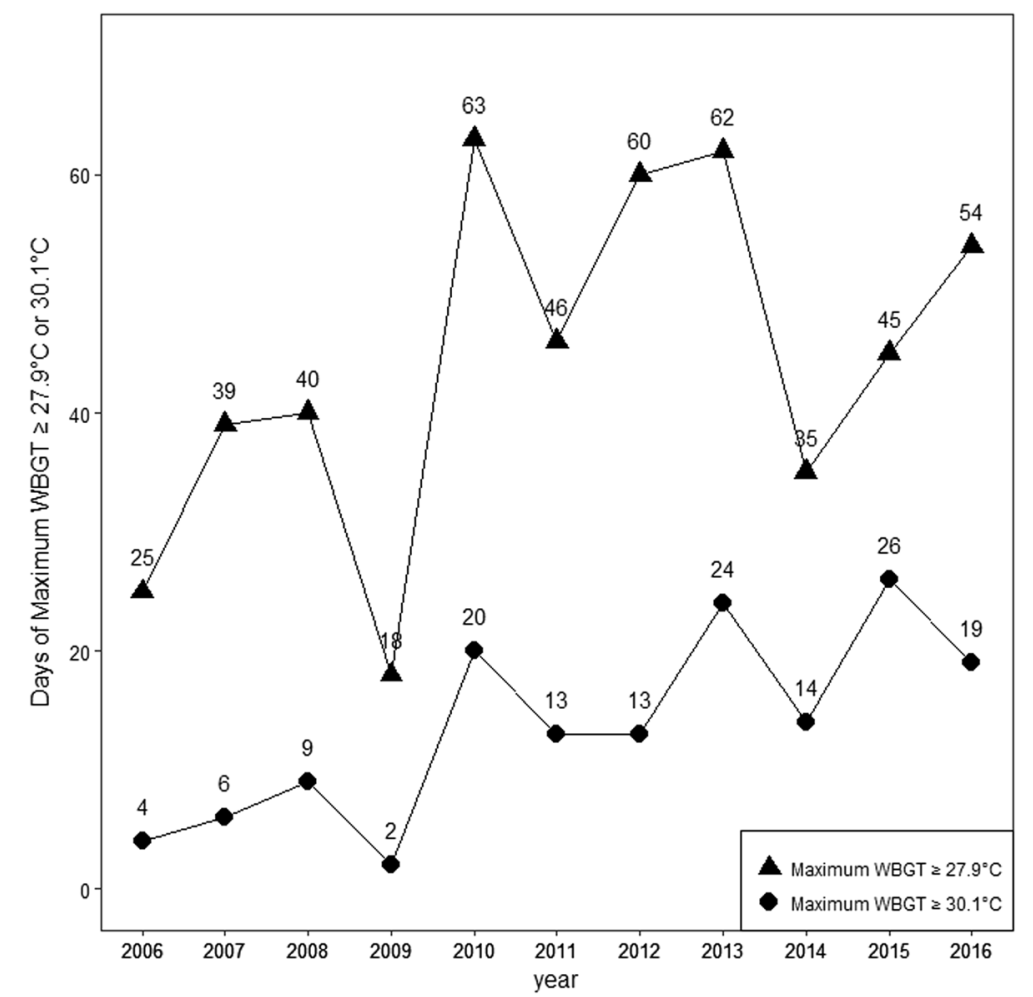

Fig. 1 Days where the maximum WBGT (wet-bulb globe temperature) index was "Cancel level for EHS risk for continuous activity and competition" (WBGT $\geq 27.9^{\circ} \mathrm{C}$ ), "very high risk," and "cancel or stop practice and competition" (WBGT $\geq 30.1^{\circ} \mathrm{C}$ ) in Tokyo from 2006 to 2016 , as per the American College of Sports Medicine criteria [15]

Differences of local climate and individual heat acclimatization status may allow activity at higher levels than outlined in the table, but athletes and coaches should consult with sports medicine staff and should remain cautious when exceeding these limits. Given that spectators and staff at the Olympic Games can probably not be expected to acclimatize to the heat, the organizing committee should also consider appropriate measures for non-acclimatized individuals.

Organizing committees can provide heat acclimation programs for staff. The National Athletic Trainers' Association in the USA, for example, has determined heat acclimatization guidelines for secondary school athletics [28]. In those guidelines, activity time is restricted during the initial exertion period. For non-acclimatized workers, outdoor working times should be limited during this time period. The appropriate selection and design of staff uniforms is also important to help reduce heat strain. These uniforms should be adapted to the heat and be wearable by all staff, while break times should be frequently provided so that staff can hydrate frequently.

For spectators, especially those from climates unlike Tokyo's, the organizing committee should broadly disseminate information and warnings on the importance of taking measures to help prevent heat illness. These include maintaining physical health by means such as getting enough sleep and nourishment, wearing sunshading implements such as wide-brimmed hats, and drinking sufficient amounts of water throughout the day.

The Tokyo Olympic organizing committee clearly needs to be mindful of the risk of heat strain when considering how to organize and schedule outdoor events. The adoption of combined and coordinated methods in accordance with the prevailing conditions will help lead the way to effective countermeasures. Organizing committees in Japan as elsewhere should pursue combined countermeasures when dealing with challenging thermal environments such as arranging shaded areas and mist showers and distributing water and/or sun-shading implements, similar to those protocols adopted during the 1996 Atlanta Summer Olympics [29]. In addition, since primary care is important for heat illness, an effective emergency medical care system needs to be implemented for the Tokyo Olympic Games. Such systems will need to be accessible, affordable, and multilingual so as to offer the greatest possible benefit to the widest range of individuals.

This study has some potential limitations that should be noted. First, WBGT has been recently challenged [4, 30], and various new tools, models, and indices for the 
assessment of human exposures to heat have now been developed [11]. Second, we calculated WBGT from available air temperature and humidity records, whereas WBGT would usually be measured by three thermometers-a natural wet bulb, a globe, and sometimes a dry bulb [12]. Despite this, the WBGT remains a widely known and useful index for helping to predict the risk of heat illness [4]. Third, although WBGT has been awarded an ISO (ISO/DIS 7933 1984) certification [12, 13] and Japan Industrial Standard (JIS) Z8504, many kinds of WBGT index meters are used. Japanese Industrial Standards Committee, for example, has recently published an electronic WBGT index meter as JIS B7922 in March 2017 [31]. WBGT should be measured by equipment which conforms to JIS Z8504 or JIS B7922. Given that it is still necessary to take measures according to the individual attributes of athletes and other participants, the use of various indicators and their applications should be expanded in order to more accurately assess the risks of heat illness.

\section{Conclusion}

Overall, our study suggests that the Tokyo 2020 Summer Olympics will be held amid extremely high WBGT conditions, including at levels deemed poorly suited for conducting sporting events. Combined efforts by all stakeholders during these events will therefore be necessary to deal with these challenging conditions so that athletes can perform their best and so heat illness can be minimized among individuals taking part in these activities. Sporting committees and the Olympic organizing committee should also consider WBGT in selecting venues and the timing of events to help minimize heat illness and enable maximum performance by athletes. Similarly, the organization of the 2020 Tokyo Olympics will need to manage heat as an occupational safety issue for staff and also provide multiple solutions to help heat illness among spectators and tourists.

\section{Abbreviations}

ACSM: American College of Sports Medicine; FIFA: Federation of International Football Association; IAAF: International Association of Athletics Federations; ITF: International Tennis Federation; JIS: Japan Industrial Standard; WBGT: Wet-bulb globe temperature

\section{Acknowledgements}

Not applicable

\section{Funding}

Financial assistance from the National Center for Global Health and Medicine, Japan, is gratefully acknowledged (27-4). The funders had no role in the study design, data collection and analysis, the decision to publish, or preparation of the manuscript.

\section{Availability of data and materials}

This study was conducted using a public database and the URL of which is referenced.

\section{Authors' contributions}

TK and KW contributed to the study conception and design. TK and SE contributed to the data collection. TK and KW contributed to the data analysis. All authors contributed to the critical discussion, manuscript revision, and decision to submit the final draft. All authors have read and approved the final manuscript.

Ethics approval and consent to participate

Not applicable

Consent for publication

Not applicable

\section{Competing interests}

The authors declare that they have no competing interests.

\section{Publisher's Note}

Springer Nature remains neutral with regard to jurisdictional claims in published maps and institutional affiliations.

\section{Author details}

${ }^{1}$ Department of Hygiene and Preventive Medicine, School of Medicine, Fukushima Medical University, Hikarigaoka 1, Fukushima 960-1295, Japan.

${ }^{2}$ Bureau of International Health Cooperation, National Center for Global Health and Medicine, 1-21-1 Toyama, Shinjuku-ku, Tokyo 162-8655, Japan. ${ }^{3}$ College of Public Health, Medical and Veterinary Sciences, James Cook University, Townsville, Australia.

Received: 4 July 2017 Accepted: 12 September 2017

Published online: 19 September 2017

\section{References}

1. National Institute for Environmental Studies. Bulletin report on heatstroke patients. http://www.nies.go.jp/gaiyo/archiv/risk8/english/index.html. Accessed 15 Sept 2017.

2. Wetterhall SF, Coulombier DM, Herndon JM, Zaza S, Cantwell JD. Medical care delivery at the 1996 Olympic Games. JAMA. 1998;279:1463-8.

3. Zhang JJ, Wang LD, Chen Z, Ma J, Dai JP. Medical care delivery at the Beijing 2008 Olympic Games. World J Emerg Med. 2011;2:267-71.

4. Racinais S, Alonso JM, Coutts AJ, Flouris AD, Girard O, González-Alonso J, et al. Consensus recommendations on training and competing in the heat. Sports Med. 2015;45:925-38.

5. Rio 2016 Organising Committee for the Olympic and Paralympic Games. Weather information for the Olympic and Paralympic Games in Rio de Janeiro 2016. https://inside.fei.org/system/files/RIO\%20Weather\%20forecast_ 0.pdf. Accessed 1 Mar 2017.

6. Smith KR, Woodward A, Lemke B, Otto M, Chang CJ, Mance AA, et al. The last Summer Olympics? Climate change, health, and work outdoors. Lancet. 2016:388:642-4.

7. Howe AS, Boden BP. Heat-related illness in athletes. Am J Sports Med. 2007;35:1384-95.

8. The Tokyo Organizing Committee of the Olympic and Paralympic Games. https://tokyo2020.jp. Accessed 2. Nov 2016

9. United Nations. World urbanization prospects: the 2014 version. 2014. https://esa.un.org/unpd/wup/Publications/Files/WUP2014-Highlights.pdf. Accessed 4 Aug 2016

10. Suzuki-Parker A, Kusaka H, Yamagata Y. Assessment of the impact of metropolitan-scale urban planning scenarios on the moist thermal environment under global warming: a study of the Tokyo metropolitan area using regional climate modeling. Adv Meteorol. 2015;2015:693754.

11. Havenith G, Fiala D. Thermal indices and thermophysiological modeling for heat stress. Compr Physiol. 2015;15:255-302.

12. Bureau of Meteorology, Australian Government. Thermal comfort observations. http://www.bom.gov.au/info/thermal_stress/. Accessed 18 Aug 2016.

13. Budd GM. Wet-bulb globe temperature (WBGT) - its history and its limitations. J Sci Med Sport. 2008:11:20-32.

14. Yaglou CP, Minard D. Control of heat casualties at military training centers. AMA Arch Ind Health. 1957:16:302-16.

15. Armstrong LE, Casa DJ, Millard-Stafford M, Moran DS, Pyne SW, Roberts WO, et al. American College of Sports Medicine position stand. Exertional heat illness during training and competition. Med Sci Sports Exerc. 2007;39:556-72. 
16. Miyake Y. Pathophysiology of heat illness: thermoregulation, risk factors, and indicators of aggravation. JMAJ. 2013;56:167-73.

17. Smith DR. Highly cited articles in environmental and occupational health, 1919-1960. Arch Environ Occup Health. 2009:64(Suppl 1):32-42.

18. FIFA. Playing in the heat. http://www.fifa.com/development/medical/ players-health/minimising-risks/heat.html. Accessed 24 Oct 2016.

19. ITA. Junior Circuit Regul. 2015; http://www.itftennis.com/media/194281/ 194281.pdf. Accessed 24 Oct 2016

20. Kashimura O, Minami K, Hoshi A. Prediction of WBGT for the Tokyo 2020 Olympic Marathon. Jpn J Biometeor. 2016;53:139-44.

21. Kashimura O, Minami K, Hoshi A. Prediction of environmental temperature in the Tokyo 2020 Olympic competition held planned period. Jpn J Sport Health Sci. 2016;53:139-44.

22. World Weather Online. http://www.worldweatheronline.com/ Accessed 4 Aug 2016.

23. Ministry of Environment. Heat illness guideline in the summer events for event organizer and facility manager. http://www.wbgt.env.go.jp/ heatillness_gline.php. Accessed 15 Sept 2017. (in Japanese).

24. Wijayanto T, Toramoto S, Wakabayashi H, Tochihara Y. Effects of duration of stay in temperate area on thermoregulatory responses to passive heat exposure in tropical south-east Asian males residing in Japan. J Physiol Anthropol. 2012:31:25.

25. Périard JD, Racinais S, Sawka MN. Adaptations and mechanisms of human heat acclimation: applications for competitive athletes and sports. Scand J Med Sci Sports. 2015;25(Suppl 1):20-38.

26. Bahr R, Reeser JC. New guidelines are needed to manage heat stress in elite sports - The Fédération Internationale de Volleyball (FIVB) Heat Stress Monitoring Programme. Br J Sports Med. 2012;46:805-9.

27. Périard JD, Racinais S, Timpka T, Dahlström Ö, Spreco A, Jacobsson J, et al. Strategies and factors associated with preparing for competing in the heat: a cohort study at the 2015 IAAF World Athletics Championships. Br J Sports Med. 2017;51:264-71.

28. Casa DJ, Csillan D, Inter-Association Task Force for Preseason Secondary School Athletics Participants. Preseason heat-acclimatization guidelines for secondary school athletics. J Athl Train. 2009;44:332-3.

29. Centers for Disease Control and Prevention. Prevention and management of heat-related illness among spectators and staff during the Olympic Games_Atlanta, July 6-23, 1996. Morb Mortal Wkly Rep. 1996;45:631-3.

30. d'Ambrosio Alfano FR, Malchaire J, Palella BI, Riccio G. WBGT index revisited after 60 years of use. Ann Occup Hyg. 2014;58:955-70.

31. National Institute of Occupational Safety and Health, Japan. Evaluation of hot environment by WBGT index and JIS of electronic WBGT index meter. https://www.jniosh.johas.go.jp/publication/mail_mag/2017/102-column-1. html. Accessed 12 Aug 2017. (in Japanese).

\section{Submit your next manuscript to BioMed Central and we will help you at every step:}

- We accept pre-submission inquiries

- Our selector tool helps you to find the most relevant journal

- We provide round the clock customer support

- Convenient online submission

- Thorough peer review

- Inclusion in PubMed and all major indexing services

- Maximum visibility for your research

Submit your manuscript at www.biomedcentral.com/submit
) Biomed Central 